\title{
International Development of Chinese Cultural Tourism Industry -Based on the Perspective of Intercultural Communication
}

\author{
Yu Yibing* \\ School of Foreign Studies, Chizhou University, Chizhou Anhui 247000, China
}

\begin{abstract}
In the context of "the Belt and Road", cultural tourism has made rapid development. The integration of culture and tourism brings new challenges to tourism industry. The major project of cultural tourism communication is how to conduct intercultural communication in the context of foreign cultures. The study analyses the intercultural communication model and the problems of cultural tourism communication from the perspective of culture shock and cultural tourism translation, and presents the specific strategies including improving the quality of text translation of cultural tourism, and strengthening effectiveness of cultural tourism communication, and cultivation of tourism talents, which helps promote the soft power of cultural tourism communication.
\end{abstract}

\section{Introduction}

With the advancement of the "Belt and Road Initiative", President $\mathrm{Xi}$ Jinping, also general secretary of the Communist Party of China (CPC) Central Committee and chairman of the Central Military Commission, once said "We will improve our ability to engage in international communication so as to tell China's stories well, make the voice of China heard, and present a true, multi-dimensional, and panoramic view of China to the world." China is a country with ancient civilization with abundant tourism culture resource, and great change has happened to Chinese tourism in that China has become a country famous for its great tourism from a country with abundant tourism resources. Therefore the international development of cultural tourism, especially the culture communication, is confronted with new challenges. High quality culture tourism service is urgently needed for the global communication and improvement of Chinese international image and status.

\section{Development of Cultural Tourism Industry and Its Culture Communication Mode}

In "the 13th Five-Year Plan", the State Council proposed that cultural tourism industry would become a pillar industry of national economy in 2000, and placed great expectations on it. China has issued a series of policies to support cultural tourism industry, which provides good policy environment for sustainable development of cultural tourism. Cultural tourism is a sunrise industry in the new situation, which is a powerful engine and important support point to adjust the industrial structure, and transfer economic development. According to the Statistics Centre of Ministry of Culture and Tourism, in 2018, domestic tourists reached 5.539billion, up 10.8 per cent from a year earlier. In 2019, the number of inbound visitors to China reached 145 million, up 2.9 per cent from a year earlier (fig1). The international tourism revenue in 2019 reached $\$ 131.3$ billion, up 3.3 per cent from a year earlier (fig 2).

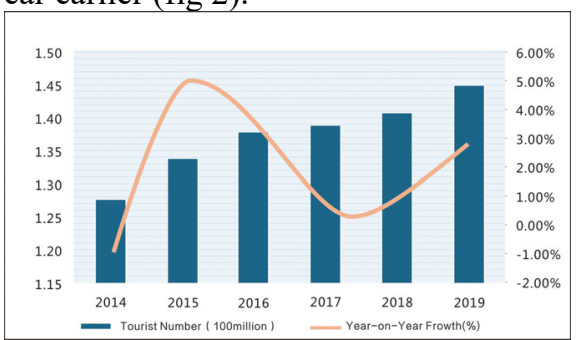

Fig1. Statistics and Increase of Inbound Visitors to China (2014-2019)

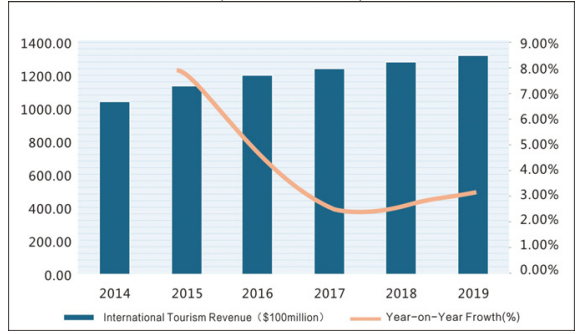

Fig2. International Tourism Revenue(2014-2019)

In 2019, there are 12402 tourist attractions with $\mathrm{A}$ level, which received 6.475 billion tourists, up $75 \%$ from the year earlier, and tourism revenue accounted to 506.572 billion Yuan, up $7.6 \%$ from the year earlier. Therefore Chinese cultural tourism industry should promote Sino-foreign cultural exchange and multilevel civilization dialogue, deepening international tourism

*Corresponding author:851825341@qq.com 
cooperation, and continuously improving international recognition of Chinese culture, Chinese spirit, Chinese values, innovating mechanism, content and models of exchange and cooperation, perfecting the system of cultural exchange and tourism promotion, so as to improve national cultural soft power, and promote the shift from the contributor to the trailblazer of international culture development. During "the 14th Five Plan", with the rise and advancement of economy and cultural revival, China enters into the new era of high-quality development and systematic development innovative development. The development strategies, including rural revitalization, "the Belt and Road", construction of ecological civilization, revitalization through science and technology, "double circulation", accelerates the integration development of culture and tourism, and its international process. Culture is the core driving force of tourism. Tourism consumer pays more and more attention to "the sense of culture" and "the sense of experience". Culture is an inner and common spiritual need, which will gradually become the tourism motivation and the final return. Cultural deposit and deep experience have become the new sources of growth of cultural tourism. The nature of tourism competition is the cultural competition, so only importance is attached to cultural attribute of tourism products, can tourism be constantly appealing. Distinguished culture resources display unique charm of regional culture, which is the core element to cultivate tourism competitiveness. For example, Xi' an has become the most popular city tourist destination during the Spring Festival for the Lunar New Year custom culture, which demonstrates the leading role of culture in the tourism. Culture is the carrier of cultural tourism, and also the core driving force of constant development of culture tourism (fig 3). During "the 14th Five Plan", culture resources should be completely exploited to promote the supply-side structural reform of tourism industry and regional economic development, with the product and service of deep integration of culture and tourism to better satisfy people's new expectation of beautiful life.

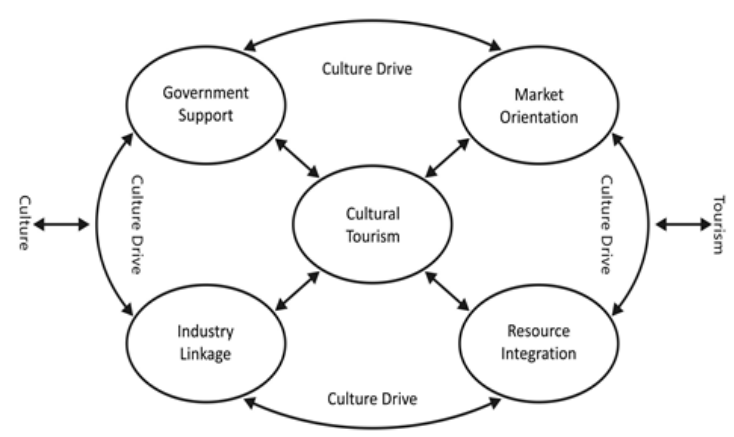

Fig 3. Development Model of Cultural Tourism

Tourism is a comprehensive and complex social activity characterized with alienation, which means tourist leaves his daily residence environment for another place, gaining a new culture experience. Therefore, tourism is also cultural phenomenon, and culture exchange activity in the process of travel is cultural tourism. American scholars Robert McIntosh and Shashkent Gerbert noted that, in fact, cultural tourism includes all aspects of tourism, by which, people can understand each other's life and thought, and it is a synthesis of phenomenon and relationship produced by inter-influence between tourists, tour facilities, host country government and reception groups in the process of attracting and receiving tourists and visitors [1]. From 2014 to 2019, inbound and outbound tourists are increasing (tab1). Cultural tourism is a complex structure system, which is a pattern of culture exchange and spread Cultural tourism is a typical cross-cultural communication in which tourists with their own culture go into an exotic cultural circle. Therefore intercultural exchange and communication is the first attribute of tourism culture. China, with a long history and rich culture, has become the preferred the destination of international tourists. Culture, as the core driving force of tourism development, improves the quality of tourism; tourism, as the carrier of culture, promotes cultural transmission. Culture translation plays more and more important role in the international travel.

Tab 1. Main Development Indexes of Chinese Tourism (2011-2019)

\begin{tabular}{|c|c|c|c|c|c|c|}
\hline- & $\begin{array}{c}\text { Domestic } \\
\text { Tourists } \\
\text { (Billion) }\end{array}$ & $\begin{array}{c}\text { Domestic } \\
\text { Tourism } \\
\text { Revenue } \\
\text { (Billion) }\end{array}$ & $\begin{array}{c}\text { Inbound } \\
\text { Tourists } \\
\text { (Million) }\end{array}$ & $\begin{array}{c}\text { Inbound } \\
\text { Tourism } \\
\text { Revenue } \\
\text { (Billion) }\end{array}$ & $\begin{array}{c}\text { Outbound } \\
\text { Tourists } \\
\text { (million) }\end{array}$ & $\begin{array}{c}\text { Total Tourism } \\
\text { Revenue } \\
\text { (Trillion) }\end{array}$ \\
\hline 2014 & 3.611 & 3031.2 & 128.5 & 105.38 & 107.28 & 3.73 \\
\hline 2015 & 3.99 & 3419.5 & 133.82 & 113.65 & 116.89 & 4.13 \\
\hline 2016 & 4.435 & 3939 & 138.44 & 120 & 122.03 & 4.69 \\
\hline 2017 & 5.001 & 4566.1 & 139.48 & 123.417 & 130.51 & 5.4 \\
\hline 2018 & 5.539 & 5127.8 & 141.2 & 127.103 & 149.72 & 5.97 \\
\hline 2019 & 6.006 & 5725.1 & 145.31 & 131.3 & 154.63 & 6.63 \\
\hline
\end{tabular}




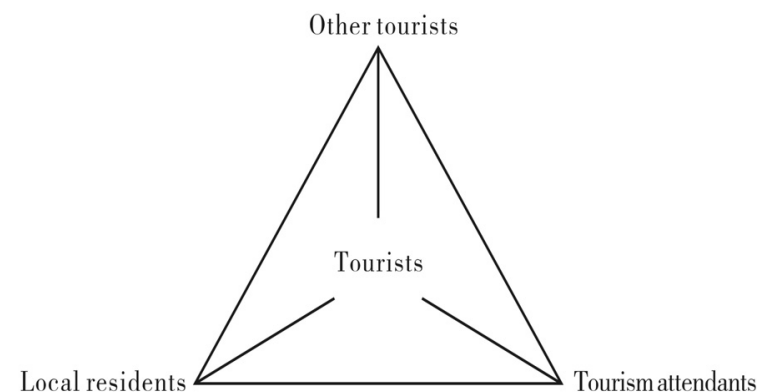

Fig 4. Triangle Structure of Intercultural Communication in Tourist Destination

Tourism itself is one of modes of intercultural communication, which is the result of cultural encounters of different regions. Intercultural communication of tourism is mainly based on the mode of interpersonal communication. There are three types of people, as the communication subjects, in the interpersonal communication of tourists in a tourist destination. Firstly, tourism attendants: They are the persons tourists have direct and frequent contact with. Secondly, local residents: They are a most important part besides the tourism workers. Thirdly, other tourists: Tourists from different regions may have interpersonal communication. The three types of people above establish a triangle structure in which they develop the relationship of social recognition and intercultural communication. The triangle structure contains 6 lines, which indicates 6 kinds of interpersonal communication relationship, and reflects various intercultural communications in the process of tourism development [2], and the cultural communication will necessarily exert influence to tourist destination. The influence of the rapid development of tourism to the culture and society of tourist destinations is one of the hot topics of tourism research, but the communication perspective of tourism, especially the intercultural communication gets little attention. The paper focuses on cultural tourism development from the perspective of intercultural communication.

\section{Culture Shock and Cultural Tourism Communication}

\subsection{Culture Shock in Cultural Tourism Communication}

The culture-motivated tourism is to experience different cultures. The greater difference is, between the culture of the tourist source region and that of tourist destination, the more curiosity and felling freshness tourists will have, which also leads to greater culture shock. Culture shock refers to the overall drop and impact someone experiences when he enters a new culture environment [3]. Cultural anthropologist Kalvero Oberg held that culture shock is caused by the inconformity between the culture the tourists have received and that of tourism destination. Tourists lose the signals and signs of social interaction they are very familiar with, which breaks the balance of their tourism recognition, and therefore they have deep anxiety for the unfamiliar social symbol.

Culture shock exerts positive and negative influence on tourists. Positive influence means the moderate culture shock can bring tourist's psychological expectation and arouse their interest in the tour process; accordingly, they can understand the culture difference and shock during their tour. While negative influence brings the obstacles of intercultural communication, which will spoil tourists' original motivation. Therefore elimination or reduction of negative influence, or transferring negative influence to positive influence, can make tourism a significant process of gaining knowledge and broadening horizon. However tourism culture communication should be based on culture identity background of tourists, sharing common ground with introduction of destination tourism culture features, which makes tourist efficiently adapt to different cultures.

Culture is transmitted by means of signs, and the signs have certain meaning in the transmission, and the meaning is cultural value. Therefore the transmission is a cultural transmission. The language sign is the basic sign system of human being; it is a major tool of interpersonal communications. Seemingly, the communications is conducted with signs; in fact, it is the communications of spirit content of human, i.e. the meaning of signs. Meaning is the recognition of natural objects and social objects. The language sign reflects regional cultural values and social regulation, and it is a tool of intercultural communication and a channel to know about foreign cultures

Information coding and decoding from different cultural background is inter-cultural communication [4]. Translation is not only to decode source language signs, but also to decode non-verbal signs-cultural connotation. In fact, language switching is superficial while culture information transmission is then essence of translation. Compared with other type of translation, tourism translation is more direct, and typical in the characteristics of inter-cultural and inter-psychological communication in all respects.

Inter-cultural communication, from cultural shock to cultural friction, misunderstanding to loving each other, is a product of culture itself to some extent. Misunderstanding is a kind of understanding, for people interpret another culture according to their own cultural tradition and thinking mode, and their original culture threshold decides their vision, choice of another culture. If a tourist goes sightseeing in a new environment, what needs firstly is that he objectively sees everything around, in fact, that is the adaptive process of culture. In a foreign culture, even if you are treated as a guest, the way, and attitude are not necessarily the same as those in your own culture. 


\subsection{Cultural Recurrence in Translation of Cultural Tourism Texts}

With the rise of national power of China, cultural influence, as a part of soft power, plays an important role abroad. In fact, language is a big obstacle in "going global" of cultural products. Language is a carrier of culture. If the carries is not well done, culture cannot go far. Tourism texts mainly belong to information and vocative type of texts, with the function and purpose of providing to the tourists all kinds of information including history, geography, humanity, and so on, which helps tourist know more about scenic spots, and arouses their interest.

How to conduct effective intercultural communication in the process of tour? On the one hand, the transmitters should have the capacity of efficiently understanding the target language and cultural background; on the other hand, the transmitters should have the proper expressing capacity according to the information receiving mode of the target audience. The purpose of tourism translation is to provide language service to the tourists in order to attain the goal of information exchange and cultural communication. Therefore, translation, based on the faithfulness to source texts, should conform to codes of language and mode of thinking of English-speaking countries.

Tourism culture communication promotes "going global "of Chinese culture, and at the same introduces the essence of international culture into our life. Communication is a process of information exchange, and also a process of culture interaction. Communication can upgrade the image of tourist destination, and improve the exchange and interaction between tourists and the people in the destination.

Effect of tourism culture communication is aimed to make information communication more fluent, concise and direct for the tourists of target language with the orientation to a specific language and culture. Effective communication mainly reflects in the identity of language and culture and thinking and values orientation, which can understand foreign culture and promote culture exchange. It is vital to establish common fields with tourists and keep information channels smooth in the language communication, in the process of which common ground is further consolidated by respecting each other's cultural difference and understanding tourists' politics, economy, history, geography ,customs and so on, so as to share cultural achievements and promote cultural enrichment and expand common ground.

\section{Strategies for Cultural Tourism Communication}

With advancement of "the Belt and Road", local tourist industry embraces opportunity and challenge. It is urgent to improve the expressive power of external publicity of cultural tourism texts. At present, the international communication of cultural tourism mainly faces three problems: firstly, the translation quality of tourism resource texts needs improvement; secondly, the effectiveness of tourism communication is not good; thirdly, high level personnel of culture communication are deficient. Recently, there has been an increasing rise in China's external publicity and culture translation, which promotes understanding of contemporary China and traditional Chinese culture. International tourism marketing and culture exchange depend largely on translation. As a matter of fact, lack of translation talents is still a choke point of tourist industry development, which is a major factor of holding back from going global of cultural tourism.

\subsection{Improving External Publicity Translation of Cultural Tourism}

"To well tell the stories of China" is a new idea based on the practice of international publicity. Language service is important fundamental facility for China to go into the world, which shoulders the responsibility of "going global " of Chinese culture. Tourism translation is mainly aimed to exchange information and arouse tourist motivation, which effectively lets tourist know about the knowledge of nature, geography, culture, customs etc., and motivates them to go sightseeing. In the multiple culture competition around the world, effective international publicity translation and promotion play an important role in development of tourism resource.

Culture exchange is a two way process with a language tool. Language is only a sign, behind which lies culture information and orientation. Translation, seemingly, is the exchange between two languages; in fact, it is the exchange of culture content that the language represents. Language is the form while culture is the content. There is great difference between cultures behind different languages; therefore, different languages and cultures cannot be totally transferred into each other.

Different geographical environments bring up different languages and cultures. Chinese culture stems from Yellow River valley, where the climate and geographical characteristics lay foundation for agricultural economy, and the corresponding customs and social regulations come into being. Western culture originates from Greek mythology, thus come into being the corresponding values and social codes. Geographical environment brings the difference in languages and cultures and aesthetic tastes, which is the great challenge for the tourism translation. In the traditional Chinese culture, south is superior to north, thus south comes before north. Chinese says "from south to north "while English says "from north to south". In Chinese culture, "east wind" implies warmth, spring, and everything coming back to life, suggesting pleasant mood. "East wind" in England, which comes from the north of European continent, is cold, unpleasant, while "west wind" from the ocean is mild and moist, so west wind heralds the advent of spring.

Therefore, translation is not only the contact between two language systems, but also different cultures, and even different civilizations. Translation process is a process of understanding and expression, which is 
decided by language elements as well social and psychological elements [3]. Understanding is basically important, ultimate expression and effective communication is more important, which helps transmit accurate information. On the contrary, translation also enriches culture, and promotes the integration and exchange of cultures. In fact, translation stems from culture exchange. How to reproduce the culture information and culture characteristics is the greatest difficulty and challenge.

Tourism texts cover a lot of ground, involving a wide range, which is aimed to transmit information and attract tourists. Culture, as the tourism core, is the source and locomotive of tourism industry. Translation is the exchange and clash of culture, and the reconstruction according target language, keeping exotic flavors, and translation lets readers experience distinctive national features and different language and culture, highlighting the uniqueness of different national language and culture.

\subsection{Strengthening Effect of Cultural Tourism Communication}

The Report of the 19th National Congress of the Communist Party of China points out "We will strengthen people-to-people and cultural exchanges with other countries, giving prominence to Chinese culture while also drawing on other cultures. We will improve our capacity for engaging in international communication so as to tell China's stories well, present a true, multi-dimensional, and panoramic view of China, and enhance our country's cultural soft power." Translation is a process of communication, which is conducted between two languages and cultures. The process of language, in fact, is a process of information exchange, which goes in the order of "coding — sending - transmitting - receiving - decoding" ."Coding" and "decoding" are the key parts. As a matter of fact, translation is a process of "coding" and "decoding". "Coding" is a process of sign transfer of purposes, intention, meaning and so on while "decoding" is a process of restoring the signs and meanings. The process is influence by various factors including values orientation, culture aesthetics, social environment, and code system, especially cultural filtration, which means interpreting the received information with one's own culture code system. If the interpretation with the language of receipts fails, misunderstanding will arise. The meaning of information of communication cannot be fully transmitted. Tourism culture translation is a process of coding and decoding of culture information of tourism resources. People always put their own needs or wisdom into coding of natural landscape or human landscape and attach certain meaning. For the individual difference and different decoding modes, tourists understand another culture according to their own cultural tradition and way of thinking.

Different culture backgrounds bring difference of communication modes, and then cause barriers and misunderstanding. In the high-context culture, much information in the communication is implied in social culture environment, or in the mind of communicators, which is transmitted through environment language or non-verbal language, while information carried by language codes is relatively less. On the contrary, in the low-context culture, the information in the communication is mainly obtained by language codes. Therefore people from different context conduct communication, the possibility of misunderstanding will increases. People from high-context culture expect more in the communication then people from low-context culture. High-context culture is implicit and veiled while low-context culture is explicit and clear. The difference of culture contexts will bring difficulty and problems to tourism culture communication.

In the intercultural communication, the clash of ideology and values is especially fierce, because different ideologies and values usually decide the value and orientation of dissemination of information. There are over 200 countries and regions in the world, with different characteristics in customs and languages and cultures and values. Culture tourism communication should overcome the difficulties and barriers, which is the precondition of effective communication.

Effective communication of cultural tourism, to some extent, decides tourists 'interpretation of tourism culture. Therefore, the communicators of tourism culture should take an active part in information communication with purposes and pertinence, and obtain the feedback in time to improve cultural tourism communication. Maximum identity of foreign culture, which is maximum common ground in the communication content between senders and receivers, is the effective communication. Cultural tourism communication is an intercultural communication activity, the capacity of intercultural communication is to think in each other's perspective, and fully experience each other's positions and views, and appreciate other cultures in an open way. Therefore, cultural tourism communication not only displays unique foreign culture, but also obtains the tourist's identity of the unique culture connotation. That is the key to effective cultural tourism communication.

\subsection{Intensifying Cultivation of Cultural Tourism Translation Talents}

The key to "going global" of the culture is to build a team of talents with excellent professional skills and broad vision for cultural exchange and communication. In order to promote the quality and efficiency of "going global" of culture, it is necessary to strengthen the cultivation of cross-cultural talents and form the guarantee of human resource supply to support "going global "of culture. The current talent structure can hardly meet the requirement by the construction of "the Belt and Road". To better promote our culture to "go global", we need the export-oriented management talents with strategic thinking who can understand transnational management and international marketing, who are good at planning foreign project and are familiar with international routines and rules. Therefore, on one hand, it is necessary to stabilize the existing cultural talents 
groups and to strengthen on-the-job training, especially cross-cultural training. On the other hand, thought cooperation with higher education institutions, it's necessary to support colleges and universities to introduce school running philosophy and science and technology of international standard to cultivate top cross-cultural talents [5].

Language is not only the transmission of information, but also the construction of social reality in international communication. There are great differences between China's discourse system and that of the west, especially with China's going to the world, other countries' misunderstanding of China has occurred from time to time. Although China's translation industry is advancing by leaps and bounds and the translation market has great potential, there is still a shortage of translators. According to statistics, there are more than 600,000 translators and 15,039 language service enterprises all over China. However, by contrast, there are less than 26,000 translation professionals in state-owned enterprises and institutions, and no more than 20,000 people have taken part in the national translation qualification (level) examination and obtained the certificate. The number of traditional institutional translators has decreased, but the socialization of translation has become more and more obvious, and the apparent prosperity hides a huge crisis. Due to the lack of effective guarantee for the quality of translators, the quality of translation is uneven, the translation market needs to be standardized and the quality of translators needs to be improved. The cultivation of translation talents includes translation project management talents. But the lack of high-level practical talents hinders China's transformation from a big translation country to a powerful translation country. There is a huge deficit in the demand and supply of advanced translation talents.

In 2006, the Ministry of education approved to set up undergraduate translation programs in domestic colleges and universities to train translation professionals. By 2019, there have been 281 undergraduate translation universities in China [6]. In 2007, the Academic Degrees Committee of the State Council approved the establishment of the master of translator and interpreter(MTI) to cultivate a high-level, application-oriented and professional translation team. At present, there are 249 MTI schools. Since the successful graduation of the first batch of translation doctorates trained in the mainland in 2008, more and more schools have been granted first-class doctoral programs in foreign language and literature. There are more than 40 schools recruiting doctoral students in translation. At present, there are about 110 doctoral students each year. At present, the training system of undergraduate, master and doctoral translators has been formed, and translation professionals have entered the stage of large-scale development. At present, there are two kinds of translation qualification examinations in China, one is the "National Accreditation Examination for Translators and Interpreters" jointly held by the Ministry of Education and Beijing Foreign Studies University, and the other is the "translation professional qualification (level) examination" held by the Ministry of Personnel. National Accreditation Examination for Translators and Interpreters (NAETI) is a national nonacademic certificate examination for all citizens, mainly tests the candidates' ability of translation and interpretation. China Accreditation Test for Translators and Interpreters -CATTI, this kind of qualification examination plays an important role in strengthening the construction of foreign language translation professional teams in China, and it scientifically, objectively and fairly evaluates the level and ability of translation professionals, which plays an important role in China's opening up and international exchanges and cooperation.

One of the key factors restricting the rapid development of China's tourism industry is the lack of talents. More talents are needed to participate in the management of tourism industry. The shortage of translation talents is not only a problem of tourism industry, but also a bottleneck that seriously restricting the external exchange of economy, culture, science and technology, education and the integration and development of national soft power. Translation plays an important role in promoting social progress. "The Belt and Road Initiative" is a major strategic move for deepening our reform. The construction of "the Belt and Road" is completely an extroverted system project, which cannot be done without translation. Translation is closely linked to the national major strategy.

Since the reform and opening up, China's translation education has made brilliant achievements. In 1979, the United Nations translation training department of Beijing Foreign Studies University was set up, which created a precedent for the cultivation of modern China's international conference interpretation. Till today, the three-level translation talent system of undergraduate, master's and doctoral has been basically completed, and a multiple level, three-dimensional and all-round training approach including BTI, MTI, MA , and PHD has been defined, Translation education has entered the stage of scale and standardization. The ability of translation professional to serve the society has been significantly enhanced, which has effectively promoted the pace of "going global" of Chinese culture [7].

With advancement of "the Belt and Road," and the development of economic globalization, cultural exchanges between countries are becoming more frequent. The cause of China's translation has witnessed unprecedented prosperity. The demand for applied translation talents is increasing. Universities have begun to reform the current traditional and single English talents training mode and are committed to the cultivation of ESP, to shoulder the mission of translation in the new era and to be the messenger of cultural exchange and civilization dissemination.

\section{Conclusion}

As an important part of cultural exchange, tourism culture plays an increasingly important role in international exchanges. Effective tourism culture communication can shape and improve the image of a 
country and region, increase international competitiveness and influence, and enhance cohesion. Also, cultural tourism communication can promote economic exchanges between countries and become a new economic growth point. Through the dissemination of tourism culture, the understanding among people of all countries can be enhanced, the prejudice and stereotype of foreign culture can be gotten rid of, the "cultural conflict" can be reduced, and the development and innovation of culture itself can be promote continuously.

Culture tourism communication plays an important role in China's foreign development and is an important way to enhance our "soft power". Only by making the public of other countries know China and understand China, can China be accepted by the international community, so as to improve the international influence of the China. The same is true in a region, with a wide range of cultural dissemination and displaying the cultural style of the region; universal recognition could be acquired ultimately. In order to truly improve the effectiveness of the communication of cultural tourism, we must make comprehensive efforts in language, culture, society and many other ways to improve the soft power of cultural tourism communication.

\section{References}

1. Robert Mackintosh, Shashkent Gerbert.Tourism: Elements $\bullet$ Practice $\bullet$ Basic Principles. Shanghai: Shanghai Culture Press, 50(1985)

2. Li Leilei. Intercultural Communication and Its Impact on Place Identity of Tourist Destinations. Journal of Shenzhen University, 17,(2):95-100(2000)
3. Zhang Hairong.Tourism Culturology. Shanghai: Fudan University, 222,(2004)

4. $\mathrm{Hu}$ Wenzhong. Introduction to Intercultural Communication. Beijing: Foreign language Teaching and Research Press,(1999)

5. Meng Jiangang. Accounting for the Duality of Translation Principles of Foreignization and Domestication of the Notion of Optimal Relevance, Chinese Translators Journal, 5,27-31(2002)

6. Chen Gang.Tourism Translation and Guide Interpreter. Beijing: China Translation and Publication Corporation, 59,(2004)

7. Ma Zhengqi. Translatology and Intercultural Communication. Shanghai: Shanghai Jiaotong University Press,(2011) 